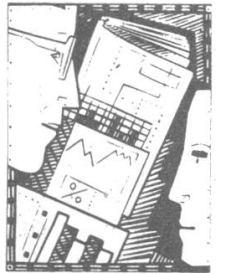

TABLE IV - New outpatient attendances by patients of Brecon Medical Group Practice

\begin{tabular}{|c|c|c|}
\hline Specialty & 1971 & $1986-7$ \\
\hline \multicolumn{3}{|c|}{ Brecon War Memorial Hospital } \\
\hline Paediatrics & & 36 \\
\hline Dermatology & & 104 \\
\hline Neurology & & 50 \\
\hline Rheumatology & & 34 \\
\hline General surgery & & 176 \\
\hline Otorhinolaryngolog & & 141 \\
\hline Orthopaedics & & 113 \\
\hline Ophthalmology & & 104 \\
\hline \multicolumn{3}{|l|}{ Obstetrics and } \\
\hline gynaecology ${ }^{\star}$ & & 475 \\
\hline Radiotherapy & & 15 \\
\hline Psychiatry & & 60 \\
\hline Total & 550 & 1358 \\
\hline \multicolumn{3}{|c|}{ Other hospitals } \\
\hline All outpatients & 900 & 538 \\
\hline Overall total & 1450 & 1896 \\
\hline
\end{tabular}

postnatal attendances. of the total hospital admissions of Brecon patients. There is considerable regional variation in hospital admission rates: 116 per 1000 for Oxford and 149 per 1000 for the North West region. ${ }^{2}$ The admission rate of 114 in Brecon is, however, considerably lower than the national average of 131 per 1000 , and it seems that this hospital must relieve the district general hospital of an appreciable workload. Several other studies have confirmed the usefulness of general practitioner hospitals and shown that direct access to hospital beds is not simply a luxury for general practitioners "playing at hospitals." ${ }^{1-10}$ The overall new outpatient attendance rate for patients in the Brecon Medical Group Practice is lower than the national average, though, again, regional variation is considerable. ${ }^{2}$ The referral rate for general practitioners in Brecon is probably lower than average (though comparison is notoriously difficult); they may have less need for specialist referral because of the facilities at Brecon War Memorial Hospital.

Figures from the Welsh Office show an average cost per inpatient day of $£ 71.07$ at Brecon War Memorial Hospital compared with $£ 88.06$ at the local district general hospital, ${ }^{11}$ and outpatient costs are estimated at $£ 20.05$ per patient attendance and $£ 29.22$ respectively. Although patients treated at the two hospitals may differ in the nature and severity of their illness, Brecon War Memorial Hospital seems to provide its services at a reasonable cost.

The future of general practitioner hospitals has been uncertain for several years despite the considerable workload they have nationally. In recent years the Department of Health has had a more favourable attitude to general practitioner hospitals ${ }^{12}$; there are, however, no specific plans for small hospitals in the white paper. ${ }^{13}$ The terms of the government's new contract for general practitioners ${ }^{14}$ may make it difficult for doctors to continue to staff general practitioner hospitals. This study again confirms that general practitioner hospitals can make a useful contribution. Working for Patients contains no reference to general practitioner hospitals, and its proposed reorganisation of family practitioner services will hinder rather than encourage the current general practitioner commitment to such hospitals.

1 Kyle D. Contribution of a general practitioner hospital. Br Med f 1971;iv: 348-51.

2 Acheson D. Variations in hospital referrals. In: Teeling Smith G, ed. Health, education and general practice. London: Office of Health Economics, 1985:21-3.

3 Wilkin D, Smith AG. Variations in general practitioners' referral rates to consultants. f R Coll Gen Pract 1987;37:350-3.

4 Johnson DB. Audit of surgical practice in a community hospital. Br Med $\mathcal{J}$ 1984;288:1293-5.

5 Cavenagh AJM. Contribution of general practitioner hospitals in England and Wales. Br Med 7 1978;ii:34-6.

6 Davies A. Coronary care in a general practitioner hospital. $\mathrm{Br} \mathrm{Med} \mathrm{J}$ 1982;285:1469-70

Harris G. The context and content of community hospital admissions. $\mathcal{J} R$ Coll Gen Pract 1986;36:363-5.

8 Kernick DP, Davies SE. The community hospital: a three year study BrMed f 1976;ii:1243-5.

9 Weston Smith J, O'Donovan JB, Hoyle G, Clegg DFG, Khalid T. Comparative study of district and community hospitals. Br Med f 1973;ii:471-4.

10 Humphreys RC. Retrospective evaluation of role of a community hospital. Br Med f 1973;iv(Suppl): 19-26.

11 Welsh Office. Welsh costing returns year ended 31 March 1987. Cardiff: HMSO, 1987.

12 Sichell GRM, Hall DH. The place of general practitioner hospitals in the organisation of hospital services. Health Trends 1982;14:21-3.

13 Secretaries of State for Health, Wales, Northern Ireland, and Scotland. Working for Patients. London: HMSO, 1988. (Cm 555.)

14 Department of Health and Welsh Office. General practice in the health service: $a$ new contract. London: DoH, 1989.

(Accepted 27 November 1989)

\title{
Appropriateness of hospital referral for hypertension
}

\section{S Juncosa, R B Jones, S M McGhee}

\section{Abstract}

Objective-To examine the efficiency of referral to an outpatient clinic and particularly the differences between referrals from general practitioners practising in health centres and those from other general practitioners.

Design-Retrospective audit of referral letters and case notes by comparison with externally set standards of appropriateness of referrals over two years.

Setting-Outpatient hypertension clinic at Western Infirmary, Glasgow.

Patients-306 Consecutive new referrals of patients over two years (1 May 1986 to 30 April 1988), for whom case notes were available in 298.

Main outcome measures-Congruence of referrals with each of two standards of appropriateness based on published opinion on specialist referral (standard 1 was stricter than standard 2) and completeness of referral letters.

Results - Of the 298 referrals, those from general practitioners accounted for 205 , from other hospital departments 68 , and from other sources 25 . Overall, $\mathbf{8 4}$ referrals of the $\mathbf{2 0 5}$ from general practice met the first standard and 134 met the second, more lenient standard. 58 Referral letters from outside the hospital had some item missing. Referrals from general practitioners working in health centres (a fifth of the total) were significantly more likely to meet both standards $(p<0.01)$ and to send a complete referral letter $(p<0.001)$ than the 145 referred by other general practitioners.
Conclusions-According to the standards used, general practitioners in health centres made more appropriate referrals, and further investigation is needed to identify the underlying factors responsible.

\section{Introduction}

The large differences among general practitioners in the proportion of their patients referred to hospital is a continuing source of debate. Marinker et al have pointed out the need for studying referrals for effectiveness and efficiency. ${ }^{2}$ Referral may be considered as effective if all the patients who need it are referred in time. On the other hand, if a high number of patients who did not need referral were referred then this process may not be efficient.

We need to know what effect the increasing move towards practising from health centres might have on referral practices. Wijkel showed that in The Netherlands general practitioners working in health centres had referral rates about $11 \%$ lower than those among other general practitioners. ${ }^{3}$ Differences in referral rates alone do not, however, indicate any differences in efficiency. The quality of referral letters has been studied extensively. ${ }^{45}$ If we assume that improving the completeness of information in the referral letter improves the use of outpatient time and resources then this also is a measure of efficiency.

We studied the efficiency of referrals to an outpatient clinic for hypertension at the Western Infirmary, Glasgow, by comparing new referrals with predefined standards and examining the completeness of the 
referral letters. In particular, we examined differences in referrals from general practitioners who were and were not practising in health centres.

\section{Patients and methods}

Clinic and patients-The Western Infirmary is a teaching hospital with a catchment population of around 250000 served by 142 general practitioners. The blood pressure clinic accepts referrals from general practitioners, internally from the hospital, and from family planning clinics and other sources. It is serviced by a long established computer system ${ }^{6}$ and manually filed computer produced summaries. Through this system we identified 306 new referrals (that is, all patients referred) during two years (1 May 1986 to 30 April 1988).

Standards for appropriateness of referrals - Two standards were devised based on published medical opinion about specialist referral. ${ }^{7-9}$. Each was designed to measure objectively whether a referral might be called appropriate according to characteristics of the referred patient. The box shows the characteristics used for the two standards; standard 1 was stricter than standard 2 and was met if any one of four conditions was satisfied.

Audit-In 205 patients the referral letters from their general practitioners were audited to extract the sex and age of the patient, the reason for referral (to compare with the standard), systolic and diastolic pressure readings, and treatment. All of these variables were considered necessary information and were used to assess whether or not the letter was "complete." If the letters contained more than one reason for referral only one was allocated, according to the priority of: (1) abnormalities related to either a cause or a complication of hypertension; these included abnormalities on urinary analysis, on electrocardiography, in creatinine concentration, on radiography, or cerebrovascular accident; (2) high diastolic pressure for age; (3) persistent high blood pressure with treatment; (4) other reasons not included in (1), (2), or (3). These included six women taking the contraceptive pill, 11 patients with minor symptoms such as anxiety, paraesthesia, and dizziness, and 16 others.

If information was not available in the referral letter it was taken from the computer summary. It is unlikely that differences in the source of recorded blood pressure (that is, general practitioners' notes and hospital records) introduced any bias. Although wide discrepancies have been found between general practitioner and hospital blood pressure readings, hospital readings are certainly not systematically lower than those in general practice. ${ }^{10}$

Analysis of referrals-In general, internal hospital

\section{Two standards for judging appropriateness of referrals to hypertension} clinic

$$
\begin{array}{ll}
\text { Standard } 1 \\
\text { Either } & \text { Aged }<40 \text { and diastolic } \\
\text { blood pressure }>104 \\
\mathrm{~mm} \mathrm{Hg}
\end{array}
$$

Or

Or Aged $>40$ and diastolic blood pressure $>114$ $\mathrm{mm} \mathrm{Hg}$

Or Any abnormality present

Or side effects after three months with treble or

more drug combination
Standard 2

Aged $<40$ and systolic blood pressure $>160$ $\mathrm{mm} \mathrm{Hg}$

Aged $<40$ and diastolic blood pressure $>95$ $\mathrm{mm} \mathrm{Hg}$

Aged $>40$ and diastolic blood pressure $>114$ $\mathrm{mm} \mathrm{Hg}$

Any abnormality present

$\begin{array}{ll}\text { Any abnormality present } & \text { Abnormality } \\ \text { Poor control or unacceptable } & \text { Follow up }\end{array}$ side effects after three months with double or more drug combination
Referred to as

Age/blood pressure referrals were without referral letters. Sixteen referrals from family planning clinics were mainly because of blood pressure problems associated with oral contraceptives. Therefore, further analysis was carried out only for referrals from general practitioners. Referrals were classed as either meeting or not meeting each standard; rëferral letters were classed as complete or not complete. Associations between these two variables and the general practitioner's practice were examined by the $t$ test and $\chi^{2}$ test.

\section{Results}

Patients-Case notes were available for audit for 298 (97\%) patients. The mean age of the patients was 48 years, $140(47 \%)$ were male, mean systolic blood pressure was $168 \mathrm{~mm} \mathrm{Hg}$ (range 112-260), and mean diastolic blood pressure was $101 \mathrm{~mm} \mathrm{Hg}$ (range 68140). The commonest referral source was general practitioners not working in health centres (145) followed by internal hospital referral (68), with general practitioners in health centres referring only 60 patients. Table I shows the characteristics of the 205 referrals from general practitioners. The proportion of males referred by general practitioners working in health centres was significantly less than that of other general practitioners $\left(\chi^{2}=6 \cdot 6, \mathrm{df}=1 ; \mathrm{p}<0 \cdot 025\right)$.

TABLE I-Characteristics of 205 patients referred by general practitioners to blood pressure clinic

\begin{tabular}{lcc}
\hline & \multicolumn{2}{c}{ General practitioners } \\
\cline { 2 - 3 } Characteristic & In health centres & Not in health centres \\
\hline No(\%) of patients & $60(20)$ & $145(49)$ \\
Mean age (years) & 46 & 48 \\
No(\%) male & $22(37)$ & $74(51)$ \\
$\begin{array}{l}\text { Mean systolic blood pressure } \\
\text { (mm Hg): }\end{array}$ & & \\
$\quad$ Systolic & 171 & 172 \\
$\quad$ Diastolic & 104 & 104 \\
\hline
\end{tabular}

Standards for appropriateness of referrals-Table II shows that $84(41 \%)$ of the 205 patients referred by general practitioners met standard 1 and $134(65 \%)$ met standard 2. Patients referred from general practitioners working in health centres were significantly more likely to meet both standard $1(57 \% v 34 \%)\left(\chi^{2}=7 \cdot 74\right.$, $\mathrm{df}=1 ; \mathrm{p}<0.01)$ and standard $2(82 \% v 59 \%)\left(\chi^{2}=9.96\right.$, $\mathrm{df}=1 ; \mathrm{p}<0.01)$ than those referred from other practices, and this difference was consistent for all reasons for referral.

Reason for referral-A significantly higher proportion of referrals from general practitioners in health centres was because of "abnormalities" $\left(\chi^{2}=5 \cdot 4, \mathrm{df}=1\right.$; $\mathrm{p}<0.025)$. Among all 298 patients, 45 were referred for abnormalities, the commonest requests being for urinary analysis (12 referrals), electrocardiography (9), determination of creatinine or urea concentration (8), cerebrovascular accident (8), radiography (5), myocardial infarction (3), retinoscopy (2), and other (11).

Completeness of referral letters-Letters from general practitioners practising in health centres were six times more likely to be complete $\left(\chi^{2}=15.3, \mathrm{df}=1 ; \mathrm{p}<0.001\right)$; only five $(8 \%)$ were incomplete compared with 53 $(37 \%)$ from other general practitioners. The referral letters for the patients who met the standards were also more likely to be complete-for example, patients who met standard 1 were three times more likely to have a complete referral letter than those who did not $\left(\chi^{2}=\right.$ $9 \cdot 0, \mathrm{df}=1 ; \mathrm{p}<0.005)$. Eighteen letters $(9 \%)$ did not mention systolic blood pressure, $12(6 \%)$ did not mention diastolic blood pressure, and 23 (11\%) did not mention any treatment. The sample included an example of the classic three word letter: "Hypertension, please see." 


\section{Discussion}

The often reported wide variation in referral rates ${ }^{1112}$ raises important questions about what is a desirable rate of referral and how much variation is acceptable. To answer this not only rates must be examined but also the appropriateness of referrals. Wilkin et al believe that any intervention in referrals should increase the proportion of patients appropriately referred and decrease that proportion inappropriately referred. ${ }^{13}$

We used published medical opinion to devise standards for referral to a blood pressure clinic. Protocols are, by nature, arbitrary but permit comparisons against consensus recommendations, which can highlight differences in practice. In this study we found that a third of the referrals surveyed did not meet even our more lenient standard. We do not know, however, what is an acceptable proportion of inappropriate referrals. General practitioners working in health centres were more likely to make referrals which met the standard and also to write comprehensive referral letters, as found by Dowie. ${ }^{14} \mathrm{~A}$ study in Holland found that referral rates from general practitioners working in health centres were lower than those from other general practitioners. ${ }^{3}$ These findings together suggest that general practitioners working in health centres have a different referral practice. They may be more efficient in that fewer inappropriate referrals are made. However, we looked at referral practice only from the outpatient clinic-that is, the receiving end of the referral chain - and we know nothing therefore about patients who were not referred. Efficiency in referral might mean that greater numbers who might benefit from referral are not being referred. Further investigation is needed to examine this and also to identify the factors that may be responsible for this apparent difference in referral behaviour. Further investigation is also needed into the unexplained difference in the proportion of males referred.

The presence of a Medical Research Council blood pressure research unit at this hospital may lead to more referrals than expected. In particular, the $23 \%$ of referrals from other hospital departments is perhaps more than that in hospitals not concerned with teaching or research and may include some patients taking part in clinical trials. Thus we cannot be sure that the findings for hypertension in Glasgow are representative of those of the rest of the United Kingdom. Nor can we be sure that these results may be applied to other specialties. If, however, we accept that between a third and a half of referrals to this clinic might be classed as inappropriate, what can be done to reduce this waste of resources? Methods available include changes in medical education, peer review, incentives, feedback from consultants, and guidelines for referral. Current

TABLE II-Reason for referral to blood pressure clinic in 205 patients by general practitioners who did and did not practise in health centres, according to standard and of appropriateness. Figures are numbers (percentages) of patients from each referral source

\begin{tabular}{|c|c|c|c|c|c|c|}
\hline \multirow{2}{*}{$\begin{array}{l}\text { Standard of } \\
\text { appropriateness }\end{array}$} & \multicolumn{5}{|c|}{ Reason for referral* } & \multirow[b]{2}{*}{ Total } \\
\hline & Age/blood pressure & Abnormality & Follow up & Other & Unknown & \\
\hline \multicolumn{7}{|c|}{ General practitioners in health centres } \\
\hline & 19 & 12 & 20 & 9 & & 60 \\
\hline Standard 1 & $10(53)$ & 12 & $11(55)$ & $1(11)$ & & $34(57)$ \\
\hline Standard 2 & $16(84)$ & 12 & $17(85)$ & $4(44)$ & & $49(82)$ \\
\hline \multicolumn{7}{|c|}{ Other general practitioners } \\
\hline & 41 & 11 & 57 & 32 & 4 & 145 \\
\hline Standard 1 & $14(34)$ & 11 & $21(37)$ & $4(13)$ & 0 & $50(34)$ \\
\hline Standard 2 & $34(83)$ & 11 & $30(53)$ & $10(31)$ & 0 & $85(59)$ \\
\hline \multicolumn{7}{|c|}{ All general practitioners } \\
\hline & 60 & 23 & 77 & 41 & 4 & 205 \\
\hline Standard 1 & $24(40)$ & 23 & $32(42)$ & $5(12)$ & 0 & $84(41)$ \\
\hline Standard 2 & $50(83)$ & 23 & $47(61)$ & $14(34)$ & 0 & $134(65)$ \\
\hline
\end{tabular}

^See box for explanation audit of referrals often focuses on numbers of referrals rather than their appropriateness and reasons for them. This is understandable because of the difficulty in defining standards for referral. None the less, we have shown that with existing published information it is possible to devise and apply a standard and thus identify a possible difference in referral practice as a starting point for further investigations.

We thank the staff of the blood pressure clinic at the Western Infirmary, Glasgow, for their help, Dr G T McInnes for his advice, and Mrs L Navin for secretarial help.

Marinker M, Wilkin D, Metcalfe DH. Referral to hospital: can we do better? Br.Med f 1988;297:461-4.

2 Cochrane AL. Effectiveness and efficiency. Random reflections on health services. Rock Carling Fellowship Monograph. London: Nuffield Provincial Hospital Trust, 1971.

$3 W_{i j k e l} \mathrm{D}$. Encouraging the development of integrated health centres: a critical analysis of lower referral rates. Soc Sci Med 1986;23:35-41.

4 Thurston CJ, Mitchell R, Little K. A study of the contents of referral letters from general practitioners to an accident and emergency department. Health (rom general practitioners to an

5 Durkin CJ, Edwards A. Referral letters from general practitioners. $f(R$ Coll Gen Pract 1975;25:532-6.

6 Kennedy F, Roy AD, Cleary JJ, Kay AW. "Switch": a system producing a full hospital case-history on computer. Lancet 1968 ;ii: 1230-3.

7 Hart JT. Hypertension. Community control of high blood pressure. Edinburgh: Churchill Livingstone, 1987

8 Barber JH, Beevers DG, Fife R, et al. Blood pressure screening and supervision in general practice. Br Med $\mathcal{F} 1979 ; \mathrm{i}: 843-6$.

9 Lothian Hypertension Group. Guidelines in the management of hypertension in general practice. Edinburgh: Joint Committee on Integration of Patient Care, 1980

10 Osbourne VL, Beevers DG. A comparison of hospital and general practice blood pressure readings using a shared-care record card. $f$ R Coll Gen Pract 1981;31:345-50.

11 Wilkin D, Smith A. Explaining the variation in general practitioner referrals to hospital. Fam Pract 1987;4:160-9.

12 Armstrong D, Britten N, Grace J. Measuring general practitioner referrals: patient, workload and list size effects. $\mathcal{F} R$ Coll Gen Pract 1988;38:494-7.

3 Wilkin D, Metcalfe DH, Markinker M. The meaning of information on GP referral rates to hospitals. Community Med 1989;11:65-70.

14 Dowie R. General practitioners and consultants: a study of outpatient referrals. London: King's Fund, 1983.

(Accepted 8 December 1989)

\section{Update box for Oxford Handbook of Clinical Medicine (2nd ed), p 491}

\section{Helicobacter pylori and relapse of peptic ulcers}

Helicobacter pylori (formerly called Campylobacter pylori) is a spiral microaerophilic flagellate organism that generates ammonia. This may neutralise gastric acid and account for the organism's unusual ecological niche in gastric mucus-secreting epithelial cells.

$H$ pylori is found in $60-95 \%$ of those with peptic ulcers. Its eradication can reduce the relapse rate in the first year from $84 \%$ to $21 \%$ in patients with positive results on culture and histology.

$H$ pylori is not found in symptomless people unless there is histological evidence of subclinical gastritis.

Eradication (and cure of ulcers) is achievable in 70\% of cases with bismuth chelate $120 \mathrm{mg} / 6 \mathrm{~h}$ given orally one hour before meals for eight weeks with oral tinidazole $500 \mathrm{mg} / 12 \mathrm{~h}$ for 10 days. $^{2}$ (Tinidazole is an antibiotic like metronidazole.)

Continuous ranitidine $(150 \mathrm{mg} /$ day $)$ gives a similar reduction in relapses, but it is expensive and means that the patient is permanently dependent on drugs. $-\mathrm{J} \mathrm{M}$ LONGMORE

1 Dooley CP, Cohen H, Fitzgibbons PL, et al. Prevalence of Helicobacter pylori infection and histological gastritis in asymptomatic persons. N Engl'Y Med 1989;231:1562-6.

2 Marshall BJ. Prospective double-blind trial of duodenal ulcer relapse after eradication of Campylobacter pylori. Lancel 1988;ii: 1437-41.

Anybody may submit an update box; all boxes are peer reviewed 